\title{
UTILIZAÇÃO DE DIFERENTES FERRAMENTAS PARA EDUCAÇÃO AMBIENTAL E DIAGNÓSTICO DE RECURSOS HÍDRICOS URBANOS
}

\author{
Armando Castello Branco Jr. \\ Universidade Federal do Triângulo Mineiro, UFTM, Iturama/MG, Brasil \\ armando.junior@uftm.edu.br
}

Kayra Helena Freitas Miranda Universidade Federal do Triângulo Mineiro, UFTM, Iturama/MG, Brasil kayrahelena123@gmail.com

Tainá Marques Sampaio Universidade Federal do Triângulo Mineiro, UFTM, Iturama/MG, Brasil taina.msampaio@gmail.com

Ana Karoline Silva Rocha Farias Universidade Federal do Triângulo Mineiro, UFTM, Iturama/MG, Brasil kaarol2310@hotmail.com

Lorraine Lacerda de Souza Universidade Federal do Triângulo Mineiro, UFTM, Uberaba/MG, Brasil lorraine.souza@uftm.edu.br

Ronier Santos Souza Universidade Federal do Triângulo Mineiro, UFTM, Iturama/MG, Brasil roniersantos1001@gmail.com

Vitor Luis Masson Universidade Federal do Triângulo Mineiro, UFTM, Iturama/MG, Brasil vitor.masson@uftm.edu.br

James Rogado

Universidade Federal do Triângulo Mineiro, UFTM, Iturama/MG, Brasil james.rogado@uftm.edu.br

\begin{abstract}
RESUMO
A água é um dos recursos naturais mais degradados pelo homem mesmo sendo um recurso renovável. A solução passa tanto por problemas técnicos como educacionais. Este trabalho tem por objetivo avaliar o uso conjunto de quatro ferramentas para realizar atividades de educação ambiental junto à comunidade do município mineiro de Iturama e o diagnóstico da qualidade da água de seus mananciais urbanos. Foram utilizadas o Mapeamento Ambiental Participativo, a Matriz SWOT/FOFA, a Análise Físico-química e Microbiológica da água e a Avaliação Ecológica Rápida de trechos dos quatro córregos urbanos. Revelou-se a percepção e visão críticas da comunidade participante em termos ambientais. Foram gerados tanto um mapa com grande riqueza de informações sobre aspectos ambientais como um plano de ação focando a melhoria de fragilidades ambientais e a manutenção das fortalezas elencadas pelos participantes. Todos os mananciais urbanos estavam contaminados por esgoto doméstico. Foi possível um ranqueamento de mananciais e trechos em termos de urgência de ações de recuperação ambiental. $\mathrm{O}$ uso conjunto das ferramentas se mostrou eficiente tanto para a promoção da consciência ambiental, como para contribuir com a gestão dos recursos hídricos do município.
\end{abstract}

Palavras-chave: Mananciais urbanos. Educação ambiental. Diagnóstico ambiental. Qualidade da água.

\section{DIFFERENT TOOLS FOR ENVIRONMENTAL EDUCATION AND DIAGNOSIS OF URBAN WATER RESOURCES}

\begin{abstract}
In spite of water been a renewable resource it is one of the most degradated natural resource by man. Solution comes through technical and educational aspects. The objective of this work is to evaluate the applicability of four tools for environmental education and water quality diagnosis of urban water springs in Iturama city, Minas Gerais State. The tools
\end{abstract}


were the Participative Environmental Mapping, the SWOT matrix, the Physical, Chemical and Microbiological water analyzes and Rapid Ecologic Assessment of parts of the four urban streams. Results revealed that community participants had critical perception of the environmental reality. A wealth environmental information map and an action plan towards weakness improvement and maintenance of the strengths were proposed. Results revealed the domestic sewage contamination of all evaluated streams. The use of the tools showed to be efficient towards the promotion of environmental consciousness besides data generated for the water resource public management of the city.

Keywords: Urban water springs. Environmental education. Environmental diagnosis. Water quality.

\section{INTRODUÇÃO}

Os recursos hídricos são abundantes mas distribuídos de forma desigual no território brasileiro. Embora a água seja um recurso natural renovável e essencial a qualquer ser vivo, vem se tornando um recurso caro que compromete não apenas a qualidade de vida das populações humanas mas também, impactando na economia e no desenvolvimento regionais (SILVA, 2012; ANA, 2019).

Tem-se que o uso do solo influencia não apenas o uso dos recursos hídricos mas também a sua disponibilidade. Assim, o diagnóstico e o planejamento são elementos essenciais na gestão destes recursos (DOWBOR e TAGNIN, 2005).

A gestão de recursos hídricos, no Brasil, definida pela Política Nacional de Recursos Hídricos na Lei no 9433/ 1997 estabelece a bacia hidrográfica como unidade de gestão e, desta forma, prevê a descentralização e a participação social efetiva da comunidade assistida por tais recursos (BRASIL, 1997).

Embora os Comitês de Bacia Hidrográfica $(\mathrm{CBH})$ tenham, por lei, abrangência em toda a bacia hidrográfica; não dispõe de recursos logísticos e humanos para os trabalhos de acompanhamento de todos os mananciais (CBH RIO Grande, 2019). Os próprios municípios, frequentemente, não demonstram o entendimento da importância de todo e qualquer manancial. Ressalta-se que além de todos os usos previstos em lei, é de mananciais superficiais que, frequentemente, é captada a água para abastecimento público e também, nesses mananciais é que se faz o lançamento de esgoto tratado.Deve-se salientar que os próprios municípios, na maioria das vezes, não possuem recursos humanos, técnicos e logísticos para fazer a análise das bacias, da ocupação do seu entorno e nem qualquer planejamento. Assim, ações sem o devido planejamento geram graves impactos para os mananciais hídricos e, frequentemente, quando a população e o poder público percebem tais impactos, a recuperação destas áreas degradadas, apesar de possível, assume custos elevados além de enormes esforços políticos e sociais.

A solução para problemas ambientais locais também é multifatorial envolvendo não apenas conhecimento técnico mas também, educação ambiental, tanto individual como coletiva. Essa educação ambiental pode acontecer de maneira formal, não-formal ou informal (GUIMARÃES, 2007; SILVA; COSTA; ALMEIDA, 2012).

Existe um relativo grande elenco de estratégias e ferramentas consagradas em educação ambiental. No entanto, as ferramentas abordadas neste trabalho se destinam originalmente ao diagnóstico ambiental como o mapeamento ambiental participativo (MAP), a análise da qualidade da água e a avaliação ecológica rápida (AER) enquanto que a matriz SWOT/ FOFA é comumente aplicada em diagnóstico e planejamento de cenários empresariais.

O MAP valoriza a percepção e o conhecimento da população envolvida cotidianamente com aspectos ambientais que podem ser, de fato, riscos ambientais ou que podem colaborar para situações que gerem riscos ou promovam degradação ambiental. De acordo com diversos autores, esta estratégia adiciona e integra as percepções individuais, mapas mentais e outros tipos de fatores aos métodos já amplamente utilizados nas pesquisas ambientais (CARPI JR. e PEREZ FILHO, 2003; DAGNINO e LADEIRA, 2005; SILVA FILHO; SILVA; CARPI JR., 2015). 
A AER está inserida no grupo dos protocolos de avaliação rápida (PAR). Os PARs foram concebidos como uma ferramenta para diagnóstico qualitativo e de baixo custo para a gestão de sistemas hídricos (BIZZO; MENEZES; ANDRADE, 2014). Os PARs tem sido utilizados para o diagnóstico ambiental de cursos d'água em diversas regiões do Brasil (CALLISTO et al., 2002; MINATTIFERREIRA; BEAUMOND, 2006; RODRIGUES; MALAFAIA; CASTRO, 2008; FRANÇA; RODRIGUES; MALAFAIA, 2013; BIZZO; MENEZES; ANDRADE, 2014; SUTIL et al., 2018).

A matriz SWOT/ FOFA é uma estratégia para o planejamento estratégico empresarial voltada para o diagnóstico, análise organizacional e elaboração de planos de ação (SANTOS e FERNANDES, 2015). Embora seja usada há menos tempo, há diversos relatos de seu uso, no Brasil, tanto no contexto do diagnóstico ambiental como na educação ambiental (ANSILAGO et al., 2008; ARAÚJO e SCHAMBORN, 2013; CARVALHO et al., 2019).

A análise da qualidade da água por parâmetros físico-químicos e microbiológicos é classicamente a ferramenta mais utilizada no diagnóstico e monitoramento de recursos hídricos sendo bem definida na forma da lei (CONAMA, 2000; 2005; 2011).

Neste contexto, o presente trabalho tem por objetivo avaliar a aplicação conjunta dessas quatro ferramentas para realizar atividades de educação ambiental junto à comunidade ituramense, no Pontal do Triângulo Mineiro, e também executar o diagnóstico da qualidade da água dos mananciais urbanos.

\section{METODOLOGIA}

Este estudo foi desenvolvido no município de Iturama-MG, localizado na microrregião de Frutal, no Pontal do Triângulo Mineiro (Figura 1a e B). Iturama é município polo possuindo uma população estimada de 40 mil habitantes, com a maior parte na zona urbana (IBGE, 2019).

Figura 1 - A. Estado de Minas Gerais e região do Triângulo Mineiro; B. Detalhe da região do Pontal do Triângulo Mineiro e o município de Iturama; C. Localização das estações de coleta (EC) nos cursos d'água avaliados.[Pontos azuis=EC do córrego Tronqueiras; pontos verdes=EC do córrego Santa Rosa; pontos amarelos=EC do córrego Quati; pontos vermelhos=EC do córrego Retirinho ]

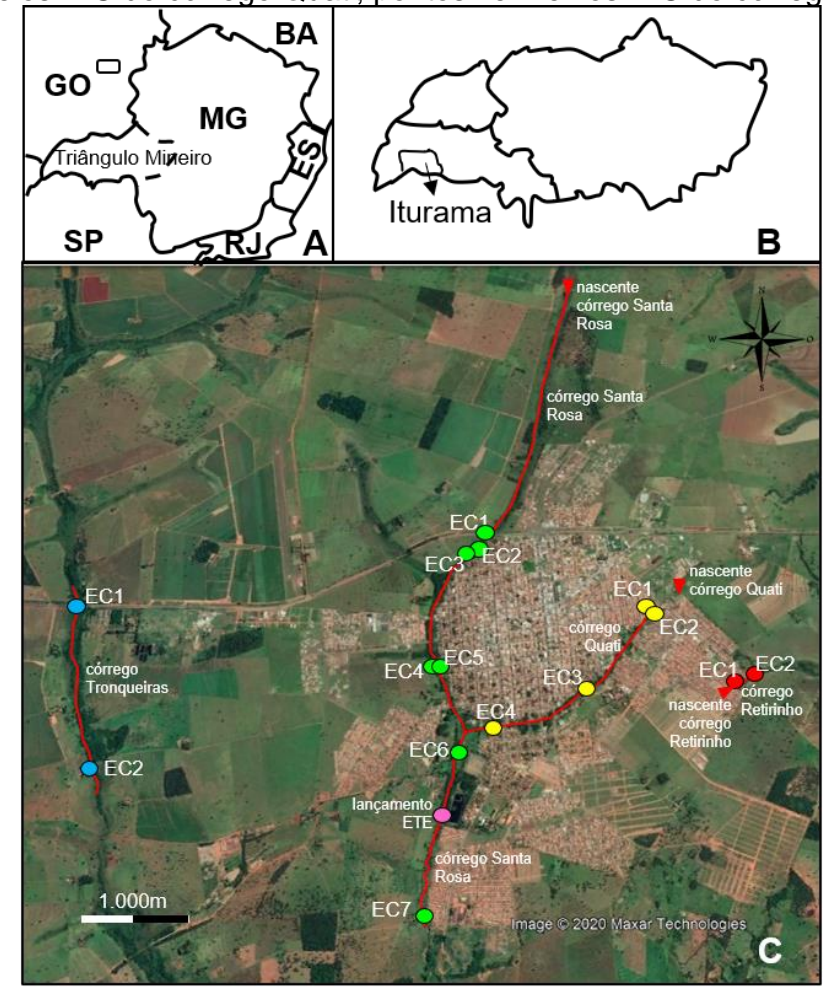

Fonte: Autores e Google Earth®. 
As ferramentas utilizadas foram o mapeamento ambiental participativo, a matriz SWOT/FOFA, a análise físico-química e microbiológica da qualidade da água e a avaliação ecológica rápida.

As ferramentas foram utilizadas em 2 oficinas realizadas com a comunidade de Iturama. Foram realizadas quatro turmas da oficina 1, ao longo do mês de março de 2019, e três turmas da oficina 2 ao longo do mês de abril de 2019. Na oficina 1 foram aplicadas as ferramentas mapeamento participativo e matriz SWOT/FOFA e, na oficina 2 as demais. Cada oficina teve duração de cerca de 3 horas.

No total, participaram 168 pessoas sendo 115 nas turmas da primeira oficina e 53 nas turmas da segunda oficina. A distribuição etária foi diferenciada entre as oficinas. Noventa e cinco por cento dos participantes das turmas da oficina 1 foram adultos (idade entre 20 e 59 anos), 4,0\% foram de idosos (idade igual ou superior a 60 anos) e 1,0\% de jovens (idade entre 15 e 19 anos) enquanto que nas turmas da oficina 2 a distribuição foi de $49,0 \%$ de jovens, $43,4 \%$ de adultos e $7,6 \%$ de idosos.

Para que esse projeto fosse desenvolvido com a comunidade, foi necessário o levantamento das lideranças municipais e de seus contatos, assim como de parceiros para locais de realização das oficinas e de uma apresentação inicial do projeto para tais lideranças. Os contatos foram obtidos pelo acesso direto às Secretarias Municipais de Educação, Saúde e Meio Ambiente além da própria Prefeitura Municipal de Iturama e Câmara de Vereadores, sempre via ofícios. Também foram feitos contatos, via ofício, com associações de moradores de bairro, entidades civis, sindicatos, Polícia de Meio Ambiente de Iturama, Associação Comercial e Industrial de Iturama (ACI-Iturama), Empresa de Assistência Técnica e Extensão Rural do Estado de Minas Gerais (EMATER) e indústrias instaladas no município. As diretorias das escolas estaduais foram contactadas após a apresentação e aprovação da proposta de trabalho para a Secretaria Estadual de Educação de Minas Gerais, via Superintendência Regional de Uberaba.

A partir da reunião de apresentação do projeto, estabeleceram-se detalhes logísticos para a execução das oficinas (datas e locais, transporte para participantes na oficina 2 e formas de divulgação). Após a definição destes aspectos, a divulgação se deu por meio de mídias sociais, rádio e jornal digital local.

\section{MAPEAMENTO AMBIENTAL PARTICIPATIVO}

Para a execução do mapeamento participativo seguiu-se o protocolo proposto por Dagnino e Carpi Jr. (2006). Os 115 participantes foram organizados em pequenos grupos, de até 10 pessoas, em que, cada grupo trabalhou com um mapa da cidade plotado em tamanho A0. Após a ambientação quando cada participante localizou pontos de referência no mapa, passou-se para a fase de identificação dos aspectos relevantes para cada participante. As marcações foram feitas em cores com legendas elaboradas por cada grupo (Figura 2A). 
Armando Castello Branco Jr. Kayra Helena Freitas Miranda Tainá Marques Sampaio

Ana Karoline Silva Rocha Farias Lorraine Lacerda de Souza

Utilização de diferentes ferramentas para educação ambiental e diagnóstico de recursos hídricos urbanos

Ronier Santos Souza

Vitor Luis Masson James Rogado

Figura 2 - Grupo de trabalho de turma da oficina 1. A. Mapeamento ambiental participativo em execução;

B. Grupo de trabalho executando ranqueamento dos aspectos ambientais na matriz SWOT/ FOFA.

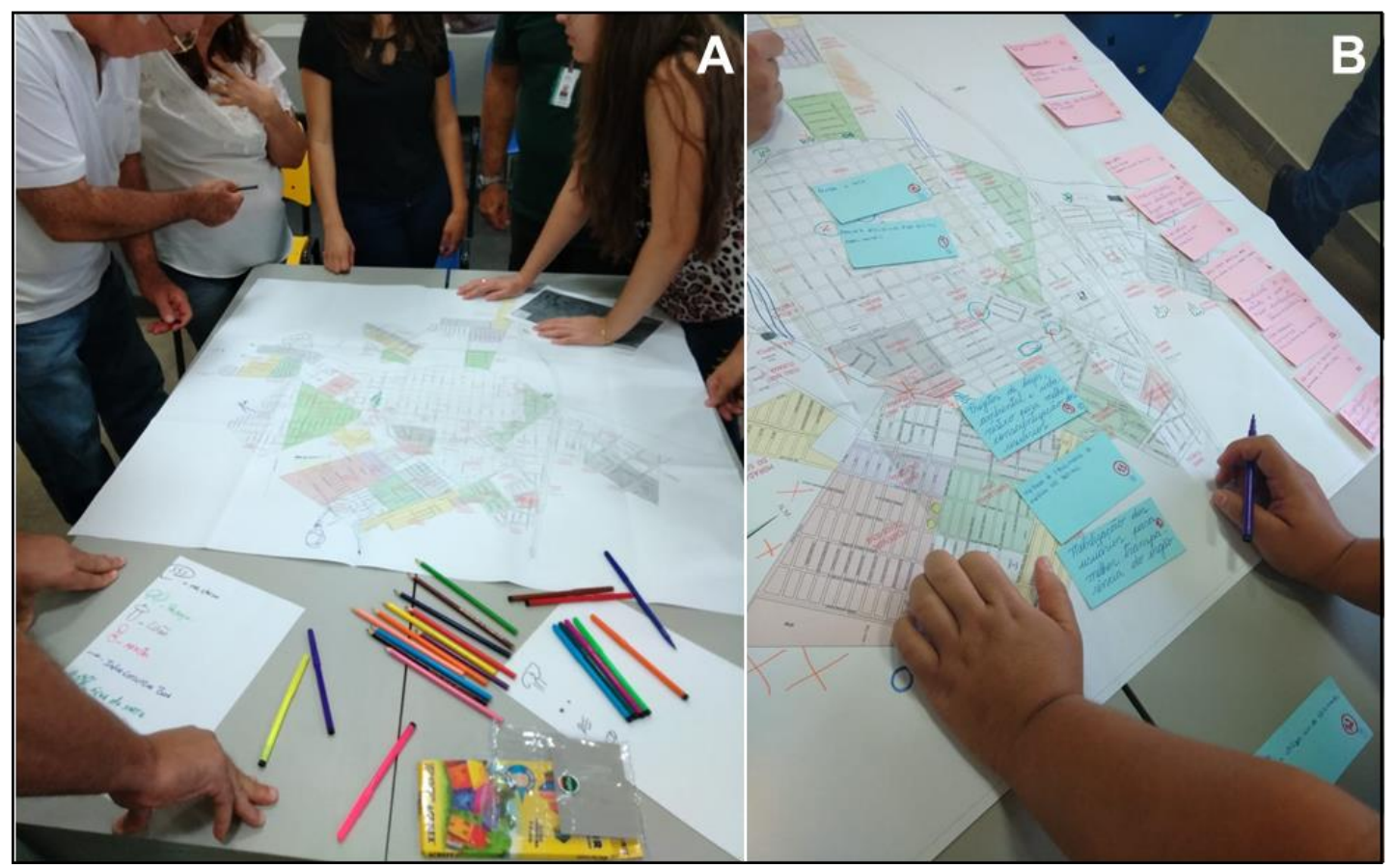

Fonte: Acervo dos Autores.

\section{Matriz SWOT/FOFA}

Seguiu-se o protocolo proposto por Carpi Jr. et al. (2014). Após a identificação e marcação dos aspectos levantados pelos 115 participantes nos mapas, procedeu-se a ferramenta Matriz SWOT (strengths, weaknesses, oportunities, threats)/ FOFA (fragilidades, oportunidades, fortalezas, ameaças), com a qual, os participantes classificaram os aspectos ambientais levantados como positivos ou negativos.

A redação dos aspectos positivos e negativos foi feita em pedaços de cartolina colorida de $5 \times 10 \mathrm{~cm}$. Os aspectos positivos (fortalezas) eram anotados em cartões verdes enquanto os negativos (fragilidades) em cartões amarelos. A partir deste ponto os participantes eram orientados a pensar em ações que pudessem transformar as fragilidades em fortalezas (oportunidades) e assim, cada ação foi redigida em um cartão azul. Analogamente, os participantes foram orientados a identificar ações que pudessem comprometer as fortalezas, assim as ameaças foram redigidas em cartões róseos. Em seguida, em cada grupo, os participantes fizeram os ranqueamento em ordem de prioridades em cada categoria (Figura 2B).

Ao final da oficina, foi solicitado que os participantes verificassem os aspectos indicados nos mapas dos demais grupos. Foi realizada uma dinâmica para avaliação da oficina na perspectiva dos participantes.

Os resultados de cada mapa foram plotados em um único para a elaboração do mapa digital com o auxílio do software Inkscape ${ }^{\circledR}$. Da mesma forma, houve a tabulação dos resultados da matriz SWOT/FOFA de cada grupo de cada turma para avaliação das intersecções e ordenamento dos aspectos. 


\section{ANÁLISE FÍSICO-QUÍMICA E MICROBIOLÓGICA}

Essa ferramenta foi desenvolvida na Oficina 2 com a participação de 53 pessoas. Nessa etapa foi fundamental a disponibilidade de transporte coletivo para conduzir os participantes para cada ponto de coleta de água.

Dessa forma, a partir dos aspectos levantados pelo mapeamento participativo foram definidos quais pontos - Estações de Coleta (EC) seriam realizados. A Figura 1C apresenta a localização das estações de coleta nos quatro mananciais avaliados, a saber, córregos Santa Rosa, Quati, Retirinho e Tronqueiras.

As amostras de água foram analisadas com testes colorimétricos para 8 parâmetros: oxigênio dissolvido (OD), amônia, nitrato, nitrito, ortofosfato, $\mathrm{pH}$, temperatura e turbidez. Todas as análises seguiram o protocolo de operação do fabricante do kit Alfakit ${ }^{\circledR}$.

As análises microbiológicas também foram realizadas por meio de avaliação colorimétrica, Colipaper $\AA$, para determinar a presença de coliformes totais e Escherichia coli, seguindo o protocolo de operação do kit.

\section{AVALIAÇÃO ECOLÓGICA RÁPIDA}

A Avaliação Ecológica Rápida (AER) consiste na mensuração da influência antrópica, em determinado ambiente. Neste trabalho foi seguido o protocolo proposto por Hannaford; Barbour; Resh (1997) e adaptado por Callisto et al. (2002). Essas análises foram feitas em trechos de até $100 \mathrm{~m}$ a montante e a jusante de cada estação de coleta de água.

O protocolo de AER, aplicado no presente trabalho com a participação de 53 pessoas, contém 22 parâmetros divididos em dois quadros. No quadro "A" são avaliadas características de trechos que indicam o nível de impactos ambientais em decorrência da atividade antrópica enquanto que, no quadro "B", são avaliadas as condições de habitats e o nível de conservação das condições naturais.

De acordo com as observações feitas a campo, são dadas pontuações. O somatório, parcial ou total, aponta o nível de interferência e condições de cada ponto de estudo. Se a somatória final for maior ou igual a 61 , significa que o ambiente está em sua forma natural sem interferência antrópica; se estiver entre 41 e 60, significa moderada interferência antrópica e se a pontuação estiver entre 0 e 40 significa elevada influência antrópica (CALLISTO et al., 2002). As pontuações finais refletem o nível de integridade ambiental e de preservação da situação ou de impacto antrópico encontrados nos trechos avaliados.

\section{RESULTADOS E DISCUSSÃO Mapeamento ambiental participativo e Matriz SWOT/FOFA}

Por conceituação destas metodologias, a participação da comunidade é fundamental no mapeamento participativo. A eficácia da Educação Ambiental e da Gestão Participativa dependem da participação cada vez maior da comunidade envolvida no cenário. No entanto, a participação da comunidade tem se mostrado muito variável. Segundo Dagnino e Carpi Jr. (2016), o número de participantes variou de 10 a 300 nos trabalhos realizados no Estado de São Paulo, no período de 1997 a 2006. Dos 16 trabalhos verificados, tem-se que a maioria dos estudos $(56,3 \%)$ aconteceu com a participação de grupos de menos de 100 pessoas e, em apenas $31,2 \%$ dos estudos houve a participação de mais de 100 pessoas nos trabalhos de mapeamento participativo.

Ressalta-se as áreas dos estudos com abrangência em áreas povoadas e extensas como, por exemplo, a região de Campinas/ SP, em área de $12.700 \mathrm{~km}^{2} \mathrm{com}$ a participação de 100 pessoas (SEVÁ FILHO, 1997) ou na bacia hidrográfica do Alto Paranapanema, em área de $22.500 \mathrm{~km}^{2}$, com a participação de 80 pessoas (ALMEIDA, 2012) e ainda na bacia dos rios Turvo e Grande, no noroeste paulista, em área de quase $16.000 \mathrm{~km}^{2} \mathrm{com}$ a participação de 40 pessoas (CARPI JR. et al., 2014). 
Armando Castello Branco Jr. Kayra Helena Freitas Miranda Tainá Marques Sampaio

Ana Karoline Silva Rocha Farias Lorraine Lacerda de Souza

Utilização de diferentes ferramentas para educação Ronier Santos Souza Vitor Luis Masson ambiental e diagnóstico de recursos hídricos urbanos James Rogado

O presente estudo abrangeu uma área de cerca de $22,0 \mathrm{~km}^{2}$ obtendo a participação de 168 pessoas no total, sendo 115 especificamente no mapeamento participativo. Dessa forma, o universo de participantes encontra-se dentro de pesquisas semelhantes realizadas por outros autores.

A Figura 3 apresenta os aspectos ambientais levantados pelos participantes de todas as turmas da oficina 1 em Iturama/ MG.

Figura 3 - Mapa final gerado após as turmas da oficina 1 no município de Iturama/ MG pela ferramenta de Mapeamento Ambiental Participativo.

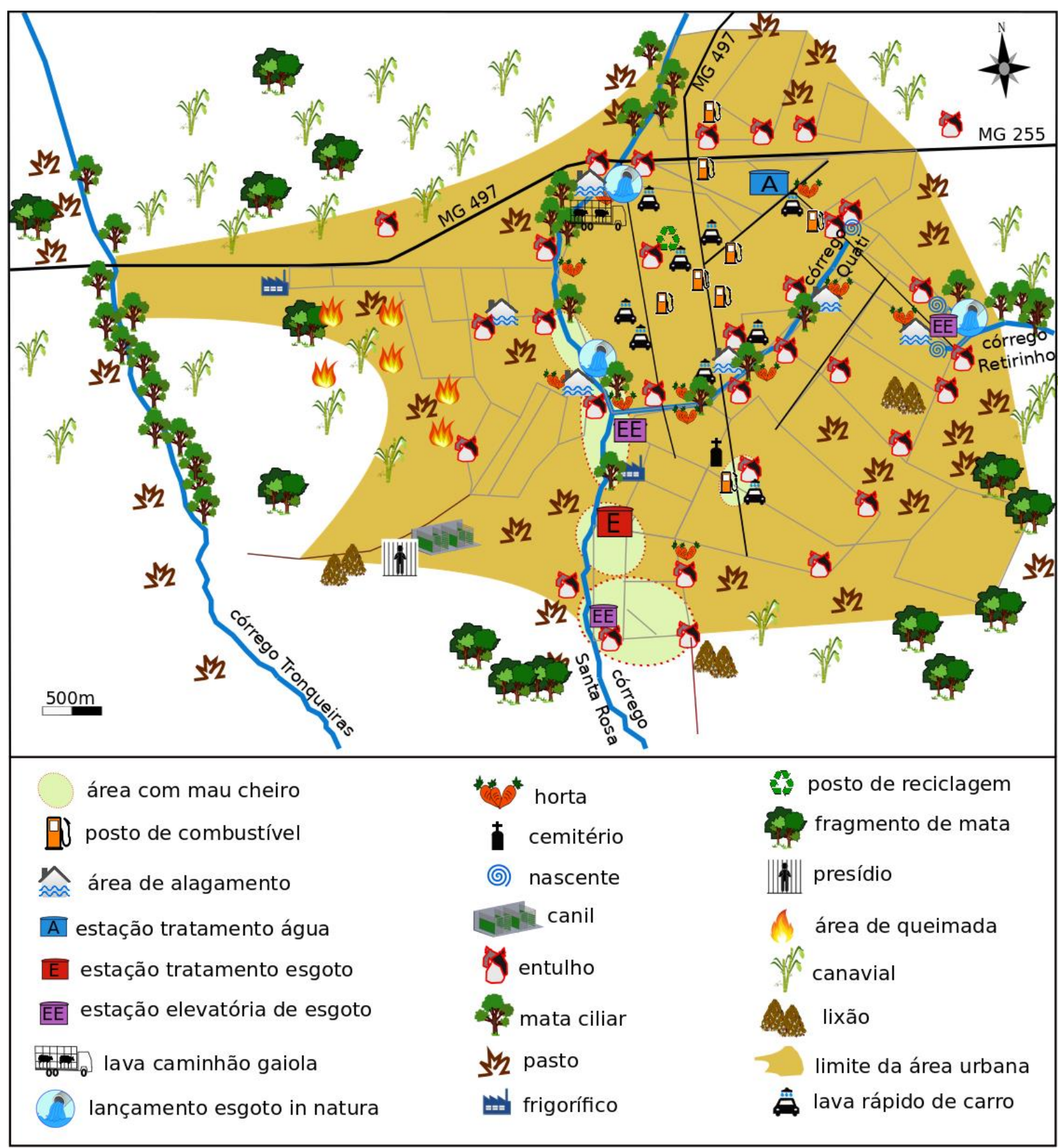

Fonte: Autores 
Resíduos sólidos (lixo no conhecimento popular) e o esgoto foram alguns dos principais aspectos ambientais elencados pela população participante. Foram evidenciados 32 pontos de disposição irregular de resíduos sólidos (lixo doméstico e entulho) além de nascentes desprotegidas e muitos trechos com pouca ou nenhuma mata ciliar ao longo dos córregos no tecido urbano. Conforme destacado pelos próprios participantes, a despeito de haver aterro sanitário, os pequenos lixões e descartes irregulares, feitos pelos próprios moradores da cidade, tornaram-se um vício mesmo sendo proibidos. Os próprios participantes salientaram que a ausência de consciência ambiental e de cidadania nas pessoas que colaboram para tais aspectos. Segundo os participantes, a coleta de lixo irregular decorrente de problemas logísticos, econômicos e de gestão colaboram para esta situação.

Outro aspecto ambiental levantado foi o mau cheiro, principalmente ao longo do córrego Santa Rosa, onde se encontram duas Estações Elevatórias de Esgoto (EEE) e a Estação de Tratamento de Esgoto (ETE). O lançamento de esgoto clandestino, tanto em tubulação direta nos córregos como em ligações na rede de drenagem pluvial, foi apontado pelos participantes assim como lançamentos de esgoto in natura pela ETE e pelas EEE. Estes aspectos foram posteriormente confirmados por ocasião dos trabalhos da oficina 2 e serão discutidos adiante.

De acordo com os participantes, foram mapeados vários lavadores de carro (lava-jatos) e de caminhões que funcionariam de maneira informal, descartando até o óleo usado da troca do óleo de motores diretamente na rede de esgoto ou diretamente no córrego. Foi relatado, inclusive, que muitos destes foram multados e mesmo assim continuam funcionando da mesma forma.

A participação social pode ser classificada não apenas quanto ao nível de adesão mas também quanto ao nível decisório que está implícito nesta participação. Existem algumas classificações baseadas em diferentes critérios (SIMÕES e SIMÕES, 2015; SOUZA, 2016). A classificação de Souza (2016) propõe 8 categorias de participação social (coerção, manipulação, informação, consulta, cooptação, parceria, delegação de poder e autogestão) em 3 níveis de decisão variando desde a ausência de poder decisório até a responsabilidade compartilhada. Na visão de Barbosa; Lopes; Carpi Jr. (2015), o presente estudo acontece na categoria de cooptação, na interface cognitiva de contribuição na qual a sociedade apresenta sugestões e demandas ao poder público.

Diversas políticas públicas brasileiras preconizam a participação social como, por exemplo, a Política Nacional de Meio ambiente (BRASIL, 1981), de Recursos Hídricos (BRASIL, 1997), de Educação Ambiental (BRASIL, 1999) e de Promoção a Saúde (BRASIL, 2014). Dessa forma, o presente trabalho está alinhado a estas políticas, destacando-se a educação ambiental não formal prevista na Lei no 9795/ 1999 (Política Nacional de Educação Ambiental) e na Lei no 9433/ 1997 (Política Nacional de Recursos Hídricos). Segundo Costa et al. (2005), a participação social também torna o mapeamento participativo em uma ação inclusiva uma vez que pode trazer pessoas que, apesar de fazerem parte da comunidade, não estavam inseridas na análise dos cenários urbanos e nem participavam das propostas de soluções para os problemas.

A Tabela 1 apresenta o ordenamento dos aspectos ambientais reconhecidos como fortalezas e fragilidades além das oportunidades e ameaças propostas pelos participantes das turmas da oficina 1. 
Armando Castello Branco Jr. Kayra Helena Freitas Miranda Tainá Marques Sampaio

Ana Karoline Silva Rocha Farias Lorraine Lacerda de Souza

Utilização de diferentes ferramentas para educação

Ronier Santos Souza

Vitor Luis Masson

ambiental e diagnóstico de recursos hídricos urbanos James Rogado

Tabela 1 - Ordenamento dos aspectos ambientais nas categorias da matriz SWOT/ FOFA das oficinas realizadas no município de Iturama/ MG quanto às bacias hidrográficas urbanas.

\begin{tabular}{|c|c|}
\hline \multicolumn{2}{|r|}{ Fortalezas } \\
\hline Ranking & Aspecto \\
\hline 1 & Presença de nascentes \\
\hline 2 & Presença de mata ciliar \\
\hline 3 & Tratamento de água ETA e tratamento de esgoto ETE \\
\hline 4 & Presença de fragmentos de vegetação \\
\hline 5 & Central de reciclagem \\
\hline 6 & Cultivo em hortas \\
\hline 7 & Presença UFTM - formadora de recursos humanos \\
\hline 8 & Aterro sanitário \\
\hline \multicolumn{2}{|r|}{ Fragilidades } \\
\hline Ranking & Aspecto \\
\hline 1 & $\begin{array}{l}\text { Disposição irregular de lixo e entulho (nascentes, margens de córregos e represas, em } \\
\text { terrenos baldios) }\end{array}$ \\
\hline 2 & $\begin{array}{l}\text { Possibilidade de contaminação do solo e da água (hospitais, postos de combustível, lava jato } \\
\text { de caminhão gaiola e cemitério) }\end{array}$ \\
\hline 3 & Possibilidade de contaminação da água por indústrias (frigorífico, usina e laticínios) \\
\hline 4 & Desmatamentos e falta de mata ciliar \\
\hline 5 & Nascentes não protegidas \\
\hline 6 & Lançamentos irregulares de esgoto (clandestino, EEE, ETE) \\
\hline 7 & Consumo excessivo de água por lava jatos \\
\hline 8 & Possibilidade de contaminação do solo e da água por agrotóxicos (canavial e hortas) \\
\hline 9 & Ocupação irregular de APP por habitações humanas \\
\hline 10 & Queimadas no pasto \\
\hline \multicolumn{2}{|r|}{ Oportunidades } \\
\hline 1 & $\begin{array}{l}\text { Conscientização ambiental da população via educação ambiental (destinação correta de lixo } \\
\text { e esgoto; preservação de mata ciliar, córregos e nascentes) }\end{array}$ \\
\hline 2 & $\begin{array}{l}\text { Promover melhor planejamento e execução da urbanização e crescimento municipal - } \\
\text { inclusive quanto ao esgoto e lixo (aterro sanitário), abastecimento de água, ocupação do } \\
\text { solo e preservação de APP, redução do consumo de água por lava-jato e lavoura }\end{array}$ \\
\hline 3 & $\begin{array}{l}\text { Fiscalização mais efetiva para não haver lançamento clandestino de esgoto, lixo e resto de } \\
\text { poda nos córregos, para a preservação das nascentes e para evitar a poluição por indústrias } \\
\text { (frigorífico, usina e laticínios) }\end{array}$ \\
\hline 4 & Fiscalização mais efetiva \\
\hline 5 & Promover a preservação das nascentes \\
\hline 6 & Dimensionamento correto da ETE e das EEE além de estudo de melhor localização da ETE \\
\hline 7 & Implantação de coleta seletiva e usina de reciclagem \\
\hline \multicolumn{2}{|r|}{ Ameaças } \\
\hline Ranking & Aspecto \\
\hline 1 & Construções próximas às nascentes e na APP \\
\hline 2 & Ineficiência do tratamento de esgoto pela ETE \\
\hline 3 & Queimadas de pasto (alterando infiltração água de chuva) \\
\hline 4 & Continuar sem mata ciliar e haver contaminação da água por agrotóxicos \\
\hline
\end{tabular}

Fonte: Autores

A coerência entre os aspectos ambientais plotados no mapeamento participativo (Figura 3) e os aspectos categorizados e ranqueados na matriz SWOT/FOFA (Tabela 1) validam estas ferramentas. Por exemplo, a plotagem da disposição de lixo e entulho em vários locais no mapa também é classificado como uma fragilidade. Da mesma forma se verifica com outros aspectos negativos (fragilidades) como a falta de mata ciliar e os lançamentos clandestinos de esgoto e também com aspectos positivos (fortalezas) como a presença de nascentes e fragmentos de mata ciliar. 
O alinhamento de ideias entre os participantes das oficinas, promovido pela dinâmica da matriz SWOT/FOFA, favorece a discussão e, de fato, provoca a geração de planos de ação. Por exemplo, as ações evitando as construções nas Áreas de Proteção Permanente (APP) de córregos e nascentes e as queimadas nas áreas de pastagem além de medidas visando a redução do desmatamento e promovendo a eficiência da ETE e a transparência de sua gestão formam um plano de ação contra as ameaças às fortalezas detectadas (nascentes, remanescentes de mata ciliar e tratamento de esgoto).

Da mesma forma, a partir de fragilidades como a disposição irregular de resíduos sólidos urbanos (lixo doméstico e entulho) nas margens dos cursos d'água e o desmatamento, principalmente em nascentes, houve a proposição de ações para mudar essa realidade, a saber, a conscientização da população pela educação ambiental, um melhor planejamento urbano, uma fiscalização mais efetiva além da preservação das nascentes e recuperação das áreas de mata ciliar.

Carpi Jr. et al. (2014) relatam que, as oportunidades elaboradas e ranqueadas pelos participantes do presente trabalho, também foram reportadas como ações que colaboraram para a melhoria do cenário ambiental de mananciais hídricos no noroeste paulista. Assim, a aplicação das ideias do plano de ação, elaborado pelos participantes, agregaria valor às mudanças necessárias no cenário atual de recursos hídricos do município de Iturama.

Fragilidades como a disposição irregular de resíduos urbanos e o desmatamento da mata ciliar além da ocupação humana de APP, também foram relatadas em outros trabalhos como responsáveis pela poluição hídrica e redução da disponibilidade hídrica em diferentes municípios (ANDRADE e FELCHAK, 2009; CARPI JR.; LEAL: DIBIESO, 2012; NÉSPOLI e ZEILHOFER, 2012; SILVA FILHO; SILVA; CARPI JR., 2015; ARAÚJO; SILVA FILHO; CARPI JR., 2017).

Araújo; Silva Filho; Carpi Jr. (2017) relataram dificuldade para a realização desta estratégia no município de Ilha Comprida, no litoral paulista. Naquele cenário, devido ao descrédito do poder público, a população não aderiu a estratégia do mapeamento participativo. Ressalta-se assim, a necessidade de confiança da comunidade alvo no poder público municipal.

Os resultados obtidos pelo mapeamento e pela matriz SWOT/ FOFA revelaram que a população participante tem percepção e visão crítica da realidade em que vivem e tem proposição de solução dos problemas que vivenciam. Diversos autores colocam que, sendo o homem o principal agente dinamizador de mudanças ambientais, ele também é o maior impactado pelas consequências destas alterações. Dessa forma, seria esperado que também participasse das soluções ou da mitigação dos impactos negativos (FREITAS e CUNHA, 2002; CARPI JR. e PEREZ FILHO, 2003; DAGNINO e LADEIRA, 2005; DAGNINO e CARPI JR., 2006).

Barbosa; Lopes; Carpi Jr. (2015) relatam a experiência positiva quanto ao uso do mapeamento participativo uma vez que os participantes puderam colaborar na gestão de recursos hídricos ao fornecer dados das situações reais em que viviam. Outros autores relatam resultados positivos com o uso desta ferramenta em diferentes regiões do Brasil (DAGNIINO e CARPI JR., 2006; 2016; CARPI JR.; LEAL; DIBIESO, 2012; SILVA FILHO; SILVA; CARPI JR., 2015; ARAÚJO; SILVA FILHO; CARPI JR., 2017).

A matriz SWOT/FOFA, ferramenta tipicamente utilizada no planejamento estratégico empresarial (AZEVEDO e COSTA, 2001; SANTOS e FERNANDES, 2015), revelou-se funcional para estudos ambientais e educacionais uma vez gerar o ordenamento de aspectos de natureza antagônica (fortalezas e fragilidades). 


\section{ANÁLISE FÍSICO-QUÍMICA E MICROBIOLÓGICA DA ÁGUA DE MANANCIAIS E AVALIAÇÃO ECOLÓGICA RÁPIDA}

Diversos autores relatam resultados da análise físico-química e microbiológica da água de mananciais para o diagnóstico da qualidade das bacias hidrográficas (LIBÂNIO; CHERNICHARO; NASCIMENTO, 2005; ANDRADE e FELCHAK, 2009; OLIVEIRA et al., 2018; SILVA et al., 2018). No entanto, relatos do uso da ferramenta de diagnóstico físico-químico e microbiológico pela comunidade não são frequentes, destacando-se o relato de Carpi Jr. e colaboradores (2014) em projeto na bacia hidrográfica dos rios Turvo e Grande, no noroeste paulista.

A opção pelo uso de testes colorimétricos com facilidade de execução, de leitura e de análise revelouse assertiva atendendo os objetivos propostos no presente trabalho.

Após a explicação sobre o significado e função de cada parâmetro, os participantes puderam compreender que, mesmo dentro dos limites legais, em vários casos, os resultados revelaram o lançamento de esgoto doméstico in natura nos córregos. A Figura 1C apresenta a localização das estações de coleta de água nos mananciais enquanto as Tabelas 2 e 3 apresentam os resultados obtidos nesta atividade nas diversas turmas da oficina 2.

A Resolução CONAMA no 357/ 2005 define que todos os cursos d'água doce do território nacional são classificados como Classe 2 salvo caracterização diferencial feita pelos Estados ou municípios. Dessa forma, todos os mananciais investigados no presente trabalho são enquadrados como da Classe 2. 
Lorraine Lacerda de Souza Ronier Santos Souza Vitor Luis Masson

Tabela 2 - Resultado da análise da qualidade da água nas estações de coleta (EC) no córrego Santa Rosa, no município de Iturama/ MG e parâmetros de qualidade da água James Rogado

\begin{tabular}{|c|c|c|c|c|c|c|c|c|}
\hline \multirow{2}{*}{$\begin{array}{l}\text { Parâmetro } \\
\text { (unidade) }\end{array}$} & \multicolumn{7}{|c|}{ Córrego Santa Rosa } & \multirow[t]{2}{*}{ Conama no357/ 2005} \\
\hline & EC1 & EC2 & EC3 & EC4 & EC5 & EC6 & EC7 & \\
\hline $\mathrm{OD}\left(\mathrm{mg} / \mathrm{L} \mathrm{O}_{2}\right)$ & 9,0 & 9,0 & 6,5 & 7,5 & 8,0 & 5,5 & 6,5 & $\geq 5,0$ \\
\hline Amônia (mg/ L N) & 0 & 3,0 & 0,1 & 0,25 & $>3,0$ & 1,0 & $>3,0$ & $\leq 3,7(\mathrm{pH} \leq 7,5)$ \\
\hline Nitrato (mg/ L N) & 0 & $>2,5$ & 0 & 0 & $>2,5$ & 2,5 & 0,7 & $\leq 10$ \\
\hline Nitrito (mg/ L N) & 0 & 0,5 & 0 & 0,01 & 0,1 & 0,1 & 0,05 & $\leq 1,0$ \\
\hline Ortofosfato (mg/ L P) & 0 & 0,16 & 0 & 0,16 & 0,32 & 0,16 & 0,32 & $\leq 0,1$ \\
\hline $\mathrm{pH}$ & 6,5 & 7,5 & 7,0 & 7,0 & 6,5 & 7,25 & 7,5 & $6,0-9,0$ \\
\hline Turbidez (NTU) & 100 & 100 & 65 & 100 & 100 & 75 & 60 & $\leq 100$ \\
\hline Temperatura $\left({ }^{\circ} \mathrm{C}\right)$ & 22,0 & 22,0 & 23,0 & 23,0 & 23,0 & 24,0 & 26,0 & Parâmetro não contemplado \\
\hline Óleos e graxas & ausente & $\mathrm{nr}$ & $\mathrm{nr}$ & ausente & ausente & presente & presente & Virtualmente ausentes \\
\hline Materiais flutuantes & ausente & $\mathrm{nr}$ & $\mathrm{nr}$ & ausente & ausente & presente & presente & Virtualmente ausentes \\
\hline Odor & ausente & $\mathrm{nr}$ & $\mathrm{nr}$ & presente & presente & presente & presente & Virtualmente ausentes \\
\hline UFC E. coli / 100mL & $0,08 \times 10^{3}$ & $0,64 \times 10^{3}$ & $0,72 \times 10^{3}$ & $4,6 \times 10^{3}$ & $7,6 \times 10^{3}$ & $8,5 \times 10^{3}$ & $10,4 \times 10^{3}$ & Parâmetro não contemplado \\
\hline UFC colif. tot./100mL & $0,96 \times 10^{3}$ & $0,64 \times 10^{3}$ & $3,52 \times 10^{3}$ & $8,96 \times 10^{3}$ & ni & ni & $\mathrm{ni}$ & $\leq 10^{3}$ UFC / $100 \mathrm{~mL}$ água \\
\hline
\end{tabular}

nr= análise não realizada; ni=número incontável de unidades formadoras de colônias. Fonte: Autores.

\begin{tabular}{lllll}
\hline Caminhos de Geografia & Uberlândia-MG & v. 22, n. 79 & Fev/2021
\end{tabular}


Lorraine Lacerda de Souza Ronier Santos Souza

Tabela 3 - Resultado da análise da qualidade da água nas estações de coleta (EC) nos córregos Quati, Retirinho e Tronqueiras no município de Iturama/ MG e parâmetros de qualidade da água (Resolução Conama nº 357/2005).

\begin{tabular}{|c|c|c|c|c|c|c|c|c|c|}
\hline \multirow{2}{*}{$\begin{array}{l}\text { Parâmetro } \\
\text { (unidade) }\end{array}$} & \multicolumn{4}{|c|}{ Córrego Quati } & \multicolumn{2}{|c|}{ Córrego Retirinho } & \multicolumn{2}{|c|}{ Córrego Tronqueira } & \multirow[t]{2}{*}{ Conama no357/ 2005} \\
\hline & EC1 & EC2 & EC3 & EC4 & EC1 & EC2 & EC1 & EC2 & \\
\hline $\mathrm{OD}(\mathrm{mg} / \mathrm{L} \mathrm{O})$ & 8,5 & 9,0 & 7,0 & 7,5 & 7,0 & 6,0 & 6,0 & 5,0 & $\geq 5,0$ \\
\hline Amônia (mg/ L N) & 1,0 & 0,25 & 3,0 & 2,0 & 3,0 & 0,35 & 0 & 2,5 & $\leq 3,7(\mathrm{pH} \leq 7,5)$ \\
\hline Nitrato (mg/ L N) & 0,1 & 0,75 & $>2,5$ & $>2,5$ & 1,75 & $>2,5$ & 0 & 1,0 & $\leq 10$ \\
\hline Nitrito (mg/ L N) & 0,03 & 0,01 & 0,4 & 0,5 & 0,2 & 0,3 & 0 & 0,25 & $\leq 1,0$ \\
\hline Ortofosfato (mg/ L P) & 0,24 & 0 & 0,24 & 0 & 0,24 & 0,24 & 0 & 0,57 & $\leq 0,1$ \\
\hline $\mathrm{pH}$ & 6,75 & 7,5 & 7,5 & 7,5 & 7,5 & 8,0 & 7,0 & 7,5 & $6,0-9,0$ \\
\hline Turbidez (NTU) & 100 & 100 & 100 & 100 & 100 & 100 & 100 & 100 & $\leq 100$ \\
\hline Temperatura $\left({ }^{\circ} \mathrm{C}\right)$ & 24,0 & 24,0 & 23,0 & 23,0 & 24,0 & 24,0 & 23,0 & 23,0 & $\begin{array}{l}\text { Parâmetro não } \\
\text { contemplado }\end{array}$ \\
\hline Óleos e graxas & ausente & $\mathrm{nr}$ & presente & presente & presente & ausente & ausente & ausente & Virtualmente ausentes \\
\hline Materiais flutuantes & ausente & $\mathrm{nr}$ & ausente & ausente & ausente & ausente & ausente & ausente & Virtualmente ausentes \\
\hline Odor & ausente & $\mathrm{nr}$ & presente & presente & presente & presente & ausente & ausente & Virtualmente ausentes \\
\hline UFC E. coli / 100mL & $1,3 \times 10^{3}$ & $\mathrm{nr}$ & $8,3 \times 10^{3}$ & $13,1 \times 10^{3}$ & $7,84 \times 10^{3}$ & $2,0 \times 10^{3}$ & $0,32 \times 10^{3}$ & $3,76 \times 10^{3}$ & $\begin{array}{l}\text { Parâmetro não } \\
\text { contemplado }\end{array}$ \\
\hline UFC colif. tot. $/ 100 \mathrm{~mL}$ & $3,36 \times 10^{3}$ & $\mathrm{nr}$ & $\mathrm{ni}$ & $17,3 \times 10^{3}$ & $8,56 \times 10^{3}$ & $3,36 \times 10^{3}$ & $0,72 \times 10^{3}$ & $7,04 \times 10^{3}$ & $\leq 10^{3} \mathrm{UFC} / 100 \mathrm{~mL}$ água \\
\hline
\end{tabular}

$\mathrm{nr}=$ análise não realizada; ni=número incontável de unidades formadoras de colônias. Fonte: Autores. 
Os parâmetros amônia, nitrito e nitrato não são apenas as principais formas de nitrogênio nas águas naturais superficiais mas também em águas residuárias (GOMES FILHO, 2013). A amônia, comum em águas superficiais, torna-se tóxica para peixes em concentrações superiores a 5,0 mg/L N além de também consumir o OD na água. Dessa forma, sua verificação na água é relevante.

Nitrito e nitrato são normalmente encontrados em baixas concentrações nas águas superficiais. $\mathrm{O}$ nitrito é uma fase intermediária de oxidação do nitrogênio sendo rapidamente oxidado em nitrato. Assim, altas concentrações de nitrito indicam descarga recente de poluente no ambiente aquático, especialmente de esgoto doméstico. Concentrações elevadas de nitrato indicam descargas antigas de poluentes nitrogenados (GOMES FILHO, 2013). O nitrato se encontra em baixas concentrações no esgoto doméstico mas em elevadas concentrações em determinados efluentes industriais nitrificados (GOMES FILHO, 2013).

Destaca-se que a ingestão de água com elevadas concentrações de nitrito e/ ou nitrato ser perniciosa para recém-nascidos e crianças levando a quadros clínicos de anóxia podendo evoluir até o óbito (ZEMAN; KROSS; VLAD, 2002; GOMES FILHO, 2013).

Embora amônia, nitrito e nitrato tenham sido detectados em concentrações dentro dos limites legais, em todos os mananciais avaliados, as variações detectadas sugerem lançamentos clandestinos em todos os mananciais. Por exemplo, no córrego Santa Rosa, as EC2 e EC5 correspondem a pontos de lançamento da rede de drenagem pluvial no córrego Santa Rosa. As concentrações nestas EC sempre estiveram mais altas e, após seu lançamento no curso d'água, respectivamente nas EC3 e EC4, houve diluição de forma a reduzir a concentração dos parâmetros avaliados (Tabela 2). Salienta-se que a diferença nos valores entre as EC5 e EC6 revela a contribuição do córrego Quati, afluente do córrego Santa Rosa (Tabela 2 e Figura 1C).

No córrego Quati, a EC1 está a 100 metros da nascente e a EC2 é em um lançamento da rede de drenagem pluvial. Verifica-se a presença de lançamento clandestino entre a EC1 e a EC3 uma vez que os valores de amônia, nitrito e nitrato aumentam, respectivamente, 3, 25 e 14 vezes (Tabela 3). Considerando o aumento no valor detectado de nitrito, sugere-se haver lançamentos clandestinos de esgoto doméstico neste trecho de cerca de $1.200 \mathrm{~m}$.

No córrego Retirinho, a brusca redução da concentração de amônia da EC1 para a EC2, provavelmente ocorra devido a oxidação da amônia em nitrito e posteriormente a nitrato. $O$ lançamento da estação elevatória de esgoto que ocorre $1 \mathrm{~m}$ a montante da EC1 fica em um bolsão d’água de forma a liberar continuamente o material contaminante. Esta forma de liberação justificaria o aumento da concentração de nitrato e nitrito entre a EC1 e a EC2 (Tabela 3).

Os resultados obtidos no córrego Tronqueiras sugerem que entre a EC1 e a EC2, distantes cerca de $1.700 \mathrm{~m}$, há lançamento de material uma vez que as concentrações detectadas de amônia, nitrito e nitrato eram iguais a zero na EC1 e, na EC2, foram detectadas as concentrações de 2,5 mg/L N, $0,25 \mathrm{mg} / \mathrm{L} \mathrm{N}$ e $1,0 \mathrm{mg} / \mathrm{L} \mathrm{N}$, respectivamente.

Outro parâmetro relevante é o ortofosfato. Ele revela o total de todos os fosfatos (mono e poli) disponíveis na água para processos biológicos. A origem deste nutriente pode ser tanto geológica como agrícola, via defensivos e fertilizantes, e de lançamentos de esgoto doméstico e industrial. No esgoto doméstico há elevada concentração de fosfatos. Essa elevada concentração pode levar a eutrofização da água dos mananciais (GOMES FILHO, 2013). A partir da concentração de fosfato pode-se calcular o índice de eutrofização do ambiente aquático, ou seja, o grau de trofia (LAMPARELLI, 2004). Quanto maior a eutrofização, melhores condições para multiplicação de algas e bactérias e, em consequência, maior o consumo do OD na água podendo levar a mortandade de vertebrados e invertebrados aquáticos.

A EC2 e a EC5, no córrego Santa Rosa, são lançamentos de drenagem pluvial e revelaram o ortofosfato em concentração 1,6 e 3,2 vezes superior ao limite legal. No entanto, devido ao fator diluição, sua concentração reduzia a jusante, nas EC3 e EC4, respectivamente (Tabela 2). Salientase que as águas do córrego Santa Rosa não revelaram ortofosfato no início de seu trajeto no tecido urbano (EC1). No entanto, 4.500m a jusante, ao sair do tecido urbano (EC7) a concentração de ortofosfato mantinha-se em 3,2 vezes superior ao limite legal (Tabela 2 e Figura 1C). A concentração de fosfato dobrou entre a EC6 e a EC7. Este aumento pode estar relacionado ao lançamento do

$\begin{array}{llllll}\text { Caminhos de Geografia } & \text { Uberlândia-MG } & \text { v. 22, n. } 79 & \text { Fev/2021 } & \text { p. 127-148 } & \text { Página } 140\end{array}$


efluente da estação de tratamento de esgoto. Salienta-se que este aspecto ambiental havia sido relatado no mapeamento participativo e na matriz SWOT/FOFA.

No córrego Quati, 100 m a jusante de sua nascente (EC1) a concentração de ortofosfato já era 2,4 vezes superior ao limite legal enquanto que no lançamento da drenagem pluvial (EC2) não se detectou a presença de ortofosfato. A concentração de ortofosfato se manteve estável até a EC3 havendo então sua redução ao longo dos 900m que a separam da EC4 (Tabela 3).

No córrego Retirinho, a concentração de ortofosfato 2,4 vezes acima do limite legal, em ambas estações de coleta, também comprova a contaminação pelo lançamento de esgoto da estação elevatória de esgoto, aspecto também levantado no mapeamento participativo.

No córrego Tronqueiras, repetiu-se o cenário verificado quanto aos parâmetros anteriores. Assim, entre a EC1, onde não se detectou o nutriente fosfato, e a EC2 houve algum lançamento de forma que a concentração detectada foi 5,7 vezes superior ao limite legal (Tabela 3).

Em todas as situações onde se detectou o ortofosfato, em qualquer manancial, sugere-se que sua origem seja de lançamentos de esgoto doméstico uma vez que os mananciais estavam percolando o tecido urbano, destacando-se que o córrego Santa Rosa, que nasce a cerca de 3.400m a montante da EC1, chega ao tecido urbano sem a detecção de ortofosfato eliminado a possibilidade de origem geológica.

Os parâmetros de $\mathrm{pH}$ e turbidez sempre se apresentaram dentro dos limites legais. $\mathrm{O}$ pH da água tem relação íntima com as reações químicas no ambiente aquático. Valores abaixo de 6,0 interferem na concentração de dióxido de carbono e de ácido carbônico enquanto que valores acima de 8,0 podem solubilizar agentes tóxicos como metais pesados, sais de carbonato e a amônia (VON SPERLING, 2007; LIBÂNIO, 2010). A turbidez, resultado da quantidade de sólidos em suspensão, tem influência direta sobre a incidência de luz no ambiente aquático e assim, sobre a taxa de fotossíntese e consequente concentração de OD (LIBÂNIO, 2010; GOMES FILHO, 2013).

O OD é um parâmetro extremamente relevante uma vez que compromete a qualidade de vida e até a existência dos diferentes grupos de organismos aquáticos aeróbicos (VON SPERLING, 2007; LIBÂNIO, 2010). Em todas as situações, neste trabalho, as concentrações de OD estiveram iguais ou acima do limite mínimo legal (5,0 mg/L O $)$ (Tabelas 2 e 3).

Os demais parâmetros, material flutuante, odor e oleosidades auxiliam na sugestão de contaminantes e, em especial, de esgoto doméstico ao se verificar o odor característico e a presença de espumas. Estes parâmetros também fazem parte do protocolo de Avaliação Ecológica Rápida aplicado no presente trabalho.

A comprovação de lançamentos de esgoto doméstico é feita por parâmetros microbiológicos. Embora o parâmetro microbiológico de coliformes totais seja definido por lei, apresenta algumas bactérias que não tem origem exclusivamente fecal. E assim, sua presença não pode comprovar a contaminação por matéria fecal. No entanto, Escherichia coli é uma bactéria de origem exclusivamente fecal e assim, sua presença confirma a contaminação por material fecal.

Ao longo de cerca de $4,5 \mathrm{~km}$, da EC1 até o ponto de saída do tecido urbano (EC7), as águas do córrego Santa Rosa apresentaram um aumento de cento e trinta vezes na concentração da enterobactéria E. coli (Tabela 2). Salienta-se que a partir da EC3, as águas do córrego Santa Rosa já se encontravam impróprias para recreação segundo os limites legais (CONAMA, 2000).

O mesmo cenário foi verificado ao longo do córrego Quati que, a menos de 100m da nascente, já se encontrava alterado. Verificou-se um aumento de 10 vezes na concentração de E. coli entre os 2.100 m que separam a EC1 da EC4, inclusive com a presença de óleos e odor na água (Tabela 3).

No córrego Retirinho, a presença de E. coli também comprova a contaminação de suas águas. A EC1 está localizada no ponto onde havia o lançamento irregular de esgoto in natura de uma estação elevatória de esgoto, previamente apontado no mapeamento participativo. A concentração da enterobactéria $E$. coli estava mais de 7 vezes acima do limite legal (Figura 1C e Tabela 3). Ao longo dos 140 m entre a EC1 e a EC2 verificou-se a redução de $25 \%$ da concentração de $E$. coli mas mesmo assim, acima do limite legal.

\begin{tabular}{|c|c|c|}
\hline Caminhos de Geografia & Uberlândia & v. 22, n. 79 \\
\hline
\end{tabular}


O último córrego avaliado foi o Tronqueiras. Suas águas são captadas para o abastecimento da cidade. Embora mais afastado do tecido urbano, está ao lado do distrito industrial onde também se encontra um frigorífico e grandes áreas de canavial (Figuras $1 \mathrm{C}$ e 3). A concentração de E. coli também elevou 11,7 vezes entre a EC1 e a EC2. Assim, comprova-se novamente o lançamento de esgoto doméstico. A EC2 do córrego Tronqueiras está à jusante do ponto de captação da água para abastecimento municipal e também do ponto de lançamento do efluente do frigorífico. Salienta-se que, de acordo com os limites legais da Resolução Conama 274/2000, as águas do córrego Tronqueiras estavam impróprias na EC2.

Ressalta-se que os aspectos levantados e mapeados pelos participantes nas atividades da oficina 1 foram comprovados nas atividades da oficina 2 sendo assim validados os aspectos mapeados.

O nível de interferência antrópica em cada trecho dos mananciais avaliados pelo protocolo de AER é apresentado na tabela 4 .

Tabela 4 - Resultado da Avaliação Ecológica Rápida (AER) nas Estações de Coleta (EC) em mananciais urbanos de Iturama, no Pontal do Triângulo Mineiro.

\begin{tabular}{cccccc}
\hline Manancial & $\begin{array}{c}\text { Estações de } \\
\text { coleta (EC) }\end{array}$ & $\begin{array}{c}\text { Pontuação } \\
\text { quadro A }\end{array}$ & $\begin{array}{c}\text { Pontuação } \\
\text { quadro B }\end{array}$ & $\begin{array}{c}\text { Pontuação } \\
\text { Total }\end{array}$ & $\begin{array}{c}\text { Influência } \\
\text { antrópica }\end{array}$ \\
\hline \multirow{3}{*}{ córrego } & EC1 & 27 & 15 & 42,3 & Moderada \\
Santa Rosa & EC4 & 24 & 28 & 52,0 & Moderada \\
& EC6 & 18 & 10 & 28,0 & Elevada \\
& EC7 & 20 & 14,5 & 34,5 & Elevada \\
\hline córrego & EC1 & 14 & 11 & 25,5 & Elevada \\
Quati & EC4 & 19 & 13 & 33,0 & Elevada \\
\hline córrego & EC1 & 15 & 14 & 29 & Elevada \\
Retirinho & EC2 & 25 & 17 & 42 & Moderada \\
\hline córrego & EC1 & 32 & 36 & 68 & Ausência \\
Tronqueiras & EC2 & 28 & 53 & 81 & Ausência \\
\hline
\end{tabular}

Fonte: Autores.

O córrego Santa Rosa possui cerca de $5.600 \mathrm{~m}$ de extensão em tecido urbano dos quais $4.500 \mathrm{~m}$ foram avaliados nas oficinas. Nos primeiros $2,4 \mathrm{~km}$ percorridos no tecido urbano, até a EC4, revelouse uma moderada influência antrópica a despeito da disposição irregular de resíduos urbanos nas suas margens, dos lançamentos de esgoto clandestinos e da pouca extensão de mata ciliar. $\mathrm{O}$ cenário piora nos últimos $2,1 \mathrm{~km}$ ao longo do tecido urbano, até a EC7, apresentando elevada influência antrópica (Figuras 1C e 3), destacando-se os aspectos de contínuo descarte irregular de lixo doméstico e entulho nas suas margens, os lançamentos de esgoto doméstico, a presença de material flutuante nas águas além de oleosidade na água e no sedimento de fundo. O crescente assoreamento e as grandes erosões nas margens devido à ausência total de mata ciliar formam a realidade deste trecho como também foi evidenciado no mapeamento participativo (Figura 3).

A pontuação total da AER também revelou elevada influência antrópica ao longo de todo o córrego Quati (Tabela 4). Alguns aspectos que contribuíram para a pontuação foram a presença de lixo nas margens e o lançamento de esgoto, a oleosidade e odor na água, o descarte de restos de animais e ossos nas suas margens além da ausência de mata ciliar. Destaca-se ainda o fato de ser um córrego retificado pelo homem.

O córrego Retirinho tem sua nascente no tecido urbano percorrendo cerca de $2 \mathrm{~km}$ até sua junção com o ribeirão Bonito. Em sua nascente (EC1) há elevada influência antrópica devido não apenas ao descarte de esgoto da EEE mas também ao odor na água e no sedimento de fundo além da grande quantidade de lixo depositado e erosão nas margens.

Nos $1.700 \mathrm{~m}$ avaliados do córrego Tronqueiras verificou-se ausência da influência antrópica pela AER a despeito da análise microbiológica comprovar a contaminação de suas águas.

Os principais parâmetros observados que comprometeram de forma elevada os mananciais estudados foram a estabilidade das margens, tipo de vegetação do entorno, habitats diversificados,

$\begin{array}{llllll}\text { Caminhos de Geografia } & \text { Uberlândia-MG } & \text { v. 22, n. } 79 & \text { Fev/2021 } & \text { p. 127-148 } & \text { Página } 142\end{array}$


tipo de ocupação do entorno e as características do fluxo de água. Outros autores relatam os mesmos cenários aqui descritos com os mesmos parâmetros (MINATTI-FERREIRA e BEAUMORD, 2006; RODRIGUES; MALAFAIA; CASTRO, 2008; 2010).

Quanto ao córrego Tronqueiras, em área de matriz agropastoril, seu nível de conservação se mostrou melhor uma vez que a mata ciliar está mais preservada.

Segundo Callisto et al. (2002), a aplicação do protocolo pelos participantes não necessita qualquer tipo de treinamento específico. Nossos resultados corroboram esta afirmação pois os participantes foram instruídos a observar a montante e a jusante de cada ponto, e anotar a classificação de acordo com as observações feitas. A facilidade oferecida pela AER permitiu aos participantes, mesmo sem qualquer tipo de treinamento prévio, chegassem ao resultado observado na tabela 4. Ressalta-se o fato de participantes sejam alfabetizados para a leitura e compreensão dos parâmetros do protocolo. Este aspecto, no entanto, não é essencial uma vez que os parâmetros poderiam até serem lidos para os participantes. Assim, essa ferramenta possibilitou a identificação e localização de trechos com demanda de ações de preservação.

A aplicação do protocolo de AER permite ao participante enxergar parâmetros mais técnicos que normalmente passariam despercebido e assim, também colaborariam no desenvolvimento de sua consciência ambiental conforme exposto por Minatti-Ferreira e Beaumord (2006).

A aplicação do protocolo de AER permite não apenas o ranqueamento de trechos de mananciais mas também dos próprios cursos d’água. Este ranqueamento facilita o ordenamento das demandas pelos gestores públicos quanto à recuperação de áreas degradadas dos mananciais. Embora todos sejam classificados como com elevada influência antrópica, o córrego Quati se revela o mais afetado pelas ações humanas (29,3 pontos), seguido pelo córrego Retirinho (35,5 pontos) e, em terceiro lugar, o córrego Santa Rosa (39,2 pontos). O córrego Tronqueiras obteve pontuação igual a 74,5 sendo assim classificando como sem influência antrópica pela AER. A análise pelos valores dos quadros $A$ e $B$ do protocolo, em separado, também geram a mesma classificação.

Durante as oficinas, tanto nas turmas da oficina 1 como na 2, a dinâmica entre os participantes era a mesma. Conforme os resultados apareciam, seja no mapeamento participativo, na matriz SWOT/FOFA, nos resultados das análises físico-químicas da água ou no preenchimento da AER, as expressões e comentários iam surgindo: “Nossa!!!", "Que coisa”, "Que absurdo!”, “E agora?”. Esta última expressão é a que ligava os resultados da oficina 2 aos da oficina 1, especialmente para aqueles que haviam participado das duas.

Percebeu-se que algumas ideias foram sendo desconstruídas como, por exemplo, de que basta a água ser transparente e sem cheiro para ser de boa qualidade, ou a de que só quem está no governo (prefeito e secretários) é que pode fazer algo pela melhoria da cidade e, em especial, em termos ambientais. Esse cenário também foi reportado por Franco et al. (2013) em trabalho desenvolvido em Conceição do Mato Dentro, município próximo à região metropolitana de Belo Horizonte/ MG.

No presente trabalho, houve um retorno de $37,5 \%$ das fichas de avaliação. O fato de que os trabalhos nas oficinas durarem 3 horas gerou uma sensação de cansaço que contribuiu para a porcentagem de retorno das fichas. Embora os participantes se manifestassem nas sessões de fechamento em cada turma, poucos ainda tinham tempo para preencher as fichas.

A população participante das oficinas apontou, tanto verbalmente como por escrito, alguns aspectos que merecem destaque. Por exemplo, a frequente manifestação de que as atividades desenvolvidas permitiram um olhar diferente sobre a cidade; e que várias pessoas passaram a perceber coisas que sempre estiveram presentes no seu dia a dia mas não as enxergavam.

Muitos participantes relataram que passaram a percebem uma relação mais direta entre as atividades humanas e suas consequências no meio ambiente; mas que também perceberam que é possível haver o desenvolvimento aliado à preservação ambiental.

Muitas pessoas declararam interesse em saber como estariam as condições dos mananciais dos municípios vizinhos, ou seja, verificou-se a expectativa do conhecimento regional e não apenas local. 
Houve um senso comum quanto a satisfação em terem participado e quanto a relevância das atividades realizadas e dos resultados obtidos, tanto para experiência e conhecimento próprios como para a conscientização ambiental. Vários participantes manifestaram a expectativa de que os resultados fossem publicizados de forma que a comunidade pudesse se engajar mais e os gestores públicos perceberem que podem fazer muito pelos recursos hídricos no município.

Interessante os relatos sobre a importância da interação com outras pessoas, de formação e histórias de vida diferentes, gerando uma riqueza de experiências, informação e conhecimento que dificilmente ocorreria de outra forma.

Por fim, muitos relataram que as ferramentas da oficina 1, mapeamento ambiental participativo e matriz FOFA, poderiam ser utilizadas para outras temáticas também relevantes para o município.

\section{CONSIDERAÇÕES FINAIS}

O uso conjunto das quatro ferramentas se mostrou uma estratégia eficiente em projetos de diagnóstico e educação ambiental. O presente trabalho teve seu foco em recursos hídricos e, em especial, em bacias hidrográficas urbanas.

Essa estratégia permitiu a promoção da sensibilização ambiental da comunidade participante. Na verdade, os relatos dos participantes permitem afirmar que a sensibilização e conscientização foi além dos participantes das oficinas uma vez terem se transformado em replicadores das experiências vividas no projeto, amplificando o alcance das informações levantadas e do entendimento técnico da realidade do município e elenco de soluções propostas por eles mesmos. Constatou-se que a comunidade que participou das atividades tem uma percepção e visão crítica da realidade em que vivem e, as ferramentas de Mapeamento Participativo e Matriz SWOT/ FOFA permitiram sua manifestação concreta e em termos mais técnicos.

Os dados levantados e propostas geradas nas oficinas contribuem para a gestão de recursos hídricos no município. O mapa e a matriz SWOT gerados, os dados da análise físico-química e microbiológica da água e a avaliação ecológica rápida tem uma riqueza de detalhamento que até os técnicos municipais desconheciam e elogiaram sobremaneira uma vez que auxiliaria muito na definição de ações específicas e monitoramento dos resultados.

Todos os cursos d'água, que percolam o tecido urbano, sofrem elevada influência das atividades humanas sendo feito um ordenamento de mananciais prioritários em termos de recuperação. 0 manancial mais afastado do tecido urbano não sofre esta pressão. No entanto, em todos os cursos d’água se verificou o lançamento de esgoto doméstico havendo a contaminação de suas águas, inclusive naquele onde há captação de água para o abastecimento municipal.

\section{AGRADECIMENTOS}

À Prefeitura Municipal de Iturama, à Secretaria Estadual de Educação de Minas Gerais, às diretorias das Escolas Estaduais Tiradentes e Joaquim Tiago Queiroz e ao Rotary Club de Iturama pelo apoio, autorização e parceria na divulgação e realização das atividades deste trabalho e à Universidade Federal do Triângulo Mineiro pela concessão de bolsa de extensão.

\section{REFERÊNCIAS}

ALMEIDA E. Riscos e alterações ambientais no Alto Paranapanema - SP. Monografia (Especialização em Gerenciamento de Recursos Hídricos e Planejamento Ambiental em Bacias Hidrográficas) - Ourinhos: UNESP. 2012. 

James Rogado

ANA - Agência Nacional de Águas. Região Hidrográfica Amazônica. 2019. Disponível em: http://www3.ana.gov.br/portal/ANA/as-12-regioes-hidrograficas-brasileiras/amazonica. Acesso em: 04 de dezembro de 2019.

ANDRADE, A. R.; FELCHAK, I. M. A poluição urbana e o impacto na qualidade da água do rio das Antas-Irati/PR. Geoambiente Jataí, v.1, n.12, p.108-132, 2009.

ANSILAGO, M. et al. Planejamento de atividades de Educação Ambiental em uma unidade de conservação sob o olhar de acadêmicos de Gestão Ambiental. Realização, Dourados, v.5, n.10, p. 19-26, 2018.

ARAUJO, M.G.; SCHWAMBORN, S.H.L. A Educação Ambiental em análise SWOT. Ambiente \& Educação, v.18, n.2, p.183-207, 2013.

ARAÚJO, V. G.; SILVA FILHO, J. L.; CARPI JR., S. Mapeamento ambiental participativo (MAP) em Ilha Comprida (SP) como subsídio à gestão e planejamento de áreas costeiras. In: I CONGRESSO NACIONAL DE GEOGRAFIA FÍSICA APLICADA, 2017, Campinas, SP. Anais [...] Campinas, SP: Universidade Estadual de Campinas, 2017. p. 2888-2899. https://doi.org/10.20396/sbgfa.v1i2017.2013

AZEVEDO, M. C.; COSTA, H. G. Métodos para avaliação de postura estratégica. Cadernos de Pesquisa em administração, São Paulo, v.8, n.2, p.1-18, 2001.

BARBOSA, F. D.; LOPES, M. C.; CARPI JR., S. Análise de alguns instrumentos de participação social na gestão dos recursos hídricos. Fórum Ambiental da Alta Paulista, v.11, n.5, p.44-53, 2015. https://doi.org/10.17271/1980082711620151235

BIZZO, M.R.O., MENEZES, J.; ANDRADE, S.F. Protocolos de Avaliação Rápida de Rios (PAR). Caderno de Estudos Geoambientais, v.4, n.1, p. 05-13, 2014.

BRASIL, Lei no 6.938, de 31 de agosto de 1981. Disponível em: http://www.planalto.gov.br/ccivil_03/Leis/L6938.htm Acesso em: 04 de abril de 2020.

BRASIL. Lei $\mathrm{n}^{\circ}$ 9.433, de 8 de janeiro de 1997. Disponível em: http://www.planalto.gov.br/ccivil_03/leis/19433.htm. Acesso em: 04 de dezembro de 2019.

BRASIL. Lei no 9.795, de 27 de abril de 1999. Disponível em: http://www.planalto.gov.br/ccivil_03/leis/l9795.htm . Acesso em: 04 de dezembro de 2019.

BRASIL - Ministério da Saúde. Portaria no 2.446, de 11 de novembro de 2014. Disponível em: http://bvsms.saude.gov.br/bvs/saudelegis/gm/2014/prt2446_11_11_2014.html Acesso em: 04 de abril de 2020.

CALLISTO, M. et al. Aplicação de um protocolo de avaliação ecológica rápida da diversidade de habitats em atividades de ensino e pesquisa (MG-RJ). Acta Limnol. Bras., v.14, n.1, p.91-98, 2002.

CARPI JR., S.; PEREZ FILHO, A. Participação popular no mapeamento de riscos ambientais em bacias hidrográficas. In: X SIMPÓSIO BRASILEIRO DE GEOGRAFIA FÍSICA APLICADA, 2003, Rio de Janeiro, RJ. Anais [...] Rio de Janeiro, RJ, 2003.

CARPI JR., S.; LEAL, A. C.; DIBIESO, E. P. Mapeamento de riscos ambientais e planejamento participativo de bacias hidrográficas: o caso do Manancial Rio Santo Anastácio, SP-Brasil. Revista Territorium, v.19, p.85-93, 2012. https://doi.org/10.14195/1647-7723 1910

CARPI JR., S. et al. Mapeamento Ambiental Participativo: Experiência de Educação ambiental na UGRH Turvo e Grande. In: DIAS, L. S.; BENINI, S. M. (Org.). Estudos ambientais aplicados em bacias hidrográficas. Tupã: ANAP, 2014, p.28 - 53.

CARVALHO, E.M. et al. Planejamento estratégico para implantação de programa de educação ambiental em uma área verde urbana. Braz. J. of Develop., Curitiba, vol. 5, n. 9, p. 14701-14721, 2019 

James Rogado

CBHRIO GRANDE - Comitê De Bacia Hidrográfica Do Rio Grande. Minas Gerais: Sobre o Comitê Histórico, 2019. Disponível em: http://cbhgrande.org.br. Acesso em: 03 de dezembro de 2019.

CONAMA - Conselho Nacional de Meio Ambiente. Resolução no 274, de 29 de novembro de 2000. Disponível em: http://www2.mma.gov.br/port/conama/legiabre.cfm?codlegi=272 Acesso em: 03 de dezembro de 2019.

CONAMA - Conselho Nacional de Meio Ambiente. Resolução n 357, de 17 de março de 2005. Disponível em: http://www2.mma.gov.br/port/conama/legiabre.cfm?codlegi=459. Acesso em: 03 de dezembro de 2019.

CONAMA - Conselho Nacional de Meio Ambiente. Resolução $n^{\circ}$ 430, de 11 de março de 2011. Disponível em: http://www2.mma.gov.br/port/conama/legiabre.cfm?codlegi=646. Acesso em:10 de setembro de 2020.

COSTA, M. C. et al. Poder público e comunidade: uma aliança possível para resolver problemas de meio ambiente? Revista Brasileira de Gestão e Desenvolvimento Regional, v.2, n.3, p. 128-152, 2005.

DAGNINO, R. S; LADEIRA, R. Esboço metodológico para uma cartografia dinâmica do ambiente na bacia hidrográfica do ribeirão das Anhumas, Campinas-SP. In: XI SIMPÓSIO BRASILEIRO DE GEOGRAFIA FíSICA APLICADA, 2005, São Paulo, SP. Anais [...] São Paulo, SP: Universidade de São Paulo, 2005.

DAGNINO, R. S.; CARPI JR., S. Mapeamento participativo de riscos ambientais na Bacia Hidrográfica do Ribeirão das Anhumas - Campinas, SP. In: III ENCONTRO DA ASSOCIAÇÃO NACIONAL DE PÓS-GRADUAÇÃO E PESQUISA EM AMBIENTE E SOCIEDADE, 2006, Brasília, DF. Anais [...] Brasília, DF: ANPPAS- Associação Nacional de Pós-Graduação e Pesquisa em Ambiente e Sociedade, 2006.

DAGNINO, R. S.; CARPI JR., S. História, desafios e perspectivas do mapeamento ambiental participativo no Estado de São Paulo. In: DIAS, L. S; BENINI, S. M (Org). Estudos ambientais aplicados em bacias hidrográficas. 2 ed. Tupã/SP: ANAP, 2016, p. 13-28.

DOWBOR, L.; TAGNIN, R. A. Administrando a água como se fosse importante: Gestão Ambiental e Sustentabilidade. São Paulo: Editora Senac, 2005.

FRANÇA, L.O., RODRIGUES, A.S.L.; MALAFAIA, G. Diagnóstico ambiental do córrego do Açude, Orizona-GO por meio de um protocolo de avaliação rápida de rios. Revista Tropica: Ciências Agrárias e Biológicas, v.7, n.1, p.32-44, 2013.

FRANCO, A. R. et al. Projeto de educação ambiental para os recursos hídricos do Parauninha: comunidades ribeirinhas como cidadãos ambientais promotores de sustentabilidade na região do Parque Estadual da Serra do Intendente. Ambiente \& Educação, v. 18, n.2, p.15-36, 2013.

FREITAS, M.; CUNHA, S. A Geomorfologia, os estudos da complexidade e o desenvolvimento sustentável. In: IV SIMPÓSIO NACIONAL DE GEOMORFOLOGIA, 2002, São Luís, MA. Anais [...] São Luís, MA: UGB, 2002, p. 1-8.

GOMES FILHO, R. R. Gestão de recursos hídricos. Conceitos e experiências em bacias hidrográficas. Goiânia: Editora América, 2013.

GUIMARÃES, M. Educação ambiental: participação para além dos muros da escola. In: MELLO, S.S.; TRAJBER, R. Vamos cuidar do Brasil: conceitos e práticas em educação ambiental na escola. Brasília Ministério da Educação, Coordenação Geral de Educação Ambiental: Ministério do Meio Ambiente, Departamento de Educação Ambiental: UNESCO, 2007, p. 85-96.

HANNAFORD, M. J.; BARBOUR, M. T.; RESH, V. H. Training Reduces Observer Variability in VisualBased Assessments of Stream Habitat. Journal of the North American Benthological Society, v.16, n.4, p.853-860, 1997. https://doi.org/10.2307/1468176

IBGE - Instituto Brasileiro de Geografia e Estatística. Minas Gerais, 2010-2018. Disponível em: http://cidades.ibge.gov.br/brasil/mg/panorama. Acesso em: 04 de dezembro de 2019.

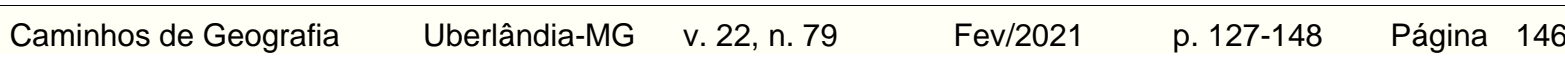


LAMPARELLI, M. C. Grau de trofia em corpos d'água do Estado de São Paulo: Avaliação dos métodos de monitoramento. Tese (Doutorado em Ciências) - São Paulo: USP, 2004.

LIBÂNIO, P. A. C.; CHERNICHARO, C. A. L.; NASCIMENTO, N. O. A dimensão da qualidade da água: Avaliação das relações entre indicadores sociais, de disponibilidade hídrica, de saneamento e de saúde pública. Engenharia Ambiental e Sanitária, v.10, n.3, p. 219-228, 2005. https://doi.org/10.1590/S1413-41522005000300006

LIBÂNIO, M. Fundamentos de qualidade e tratamento de água. 3.ed. São Paulo: Editora Átomo, 2010.

MINATTI-FERREIRA, D. D.; BEAUMORD, A. C. Adequação de um protocolo de avaliação rápida de integridade ambiental para ecossistemas de rios e riachos: aspectos físicos. Revista Saúde e Ambiente, v.7, n.1, p.39-47, 2006.

NÉSPOLI, G. R. C. B.; ZEILHOFER, P. Sistema de indicadores socioambientais para planejamento e gestão urbana. In: PHILLIPI JR., A.; MALHEIROS, T.B. Indicadores de Sustentabilidade e Gestão ambiental. Barueri: Editora Manole, 2012, p. 264-270.

OLIVEIRA, E.C. et al. Diagnóstico temporal e espacial da qualidade da água superficial em uma microbacia urbana. Revista Ibero Americana de Ciências Ambientais, v.9, n.8, p.57-69, 2018.

RODRIGUES, A. S. L.; MALAFAIA, G. C.; CASTRO, P. T. A. Avaliação ambiental de trechos de rios na região de Ouro Preto-MG através de um protocolo de avaliação rápida. Revista de Estudos Ambientais, v.10, n.1, p.74-83, 2008.

A importância da avaliação do habitat no monitoramento da qualidade dos recursos hídricos: uma revisão. Revista de Saúde e Biologia, v.5, n.1, p.26-42, 2010.

SANTOS, M. C.; FERNANDES, M. E. B. A. Ferramenta análise SWOT no processo de formulação das ações estratégicas nas pequenas empresas. Um estudo de caso na empresa Empreiteira Magnujd São Paulo Ltda. Revista FATEC Sebrae em debate: gestão, tecnologias e negócios, v.2, n.2, p.111-126, 2015.

SEVÁ FILHO, A. Riscos técnicos coletivos ambientais na região de Campinas. NEPAMUNICAMP, $1997 . \quad$ Disponível em: http://www.fem.unicamp.br/ seva/riscos_ambientais_Campinas_1997.pdf. Acesso em: 14 de janeiro de 2020.

SILVA, B. B. et al. Análise da qualidade da água do Ribeirão Tronqueiras. Revista Ibero Americana de Ciências Ambientais, v.9, n.8, p.11-25, 2018.

SILVA, C. H. R. T. Recursos Hídricos e Desenvolvimento Sustentável no Brasil. Boletim legislativo $\mathbf{n}^{\circ}$ 23, Senado Federal, 2012. Disponível em: https://www2.senado.leg.br/bdsf/bitstream/handle/id/242667/Boletim2012.23.pdf?sequence=1\&isAllow ed=y Acesso em: 20 de novembro de 2019.

SILVA, L. O.; COSTA, A. P. L.; ALMEIDA, E. A. Educação ambiental: o despertar de uma proposta crítica para a formação do sujeito ecológico. Revista Holos, v.1, p.110-126, 2012. https://doi.org/10.15628/holos.2012.659

SILVA FILHO, J. L.; SILVA, A. M. A.; CARPI JR., S. Mapeamento participativo aplicado ao estudo de riscos ambientais no bairro rural Sítio Novo, São José do Rio Pardo/SP. Fórum Ambiental do Alta Paulista, v.11, n.4, p.55-67, 2015. https://doi.org/10.17271/1980082711420151247

SIMÕES, G. L. S.; SIMÕES, J. M. Reflexões sobre o conceito de participação social no contexto brasileiro. In: VII JORNADA INTERNACIONAL DE POLÍTICAS PÚBLICAS, São Luís, MA. 2015. Anais [...]. São Luís, MA: Universidade Federal do Maranhão, 2015.

SOUZA, M. L. Mudar a cidade - Uma introdução crítica ao planejamento e à gestão urbanos. Rio de Janeiro: Bertrand Brasil, 2016. 
Armando Castello Branco Jr. Kayra Helena Freitas Miranda Tainá Marques Sampaio Ana Karoline Silva Rocha Farias Lorraine Lacerda de Souza Ronier Santos Souza ambiental e diagnóstico de recursos hídricos urbanos Vitor Luis Masson

SUTIL, T. et al. Análise da Qualidade Hídrica do Rio Tega, Caxias do Sul-RS, Brasil. R. gest. sust. ambient., Florianópolis, v.7, n.2, p.124-142, 2018. https://doi.org/10.19177/rgsa.v7e22018124-142

VON SPERLING, M. Estudos e modelagem da qualidade da água de rios. Princípios do tratamento de águas residuárias vol. 7, Belo Horizonte: Editora UFMG, 2007.

ZEMAN, C. L.; KROSS, B.; VLAD, M. A. A nested case-control study of methemoglobinemia risk factors in cildren of Transylvania. Romania. Environmental Health Perspectives, v.110, n.8, p. 817822, 2002. https://doi.org/10.1289/ehp.02110817

Recebido em: 06/04/2020

Aceito para publicação em: 16/09/2020 